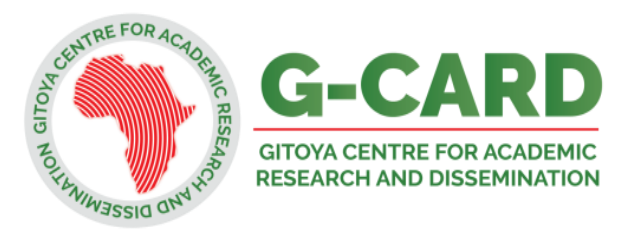

\title{
Adequacy of Laboratory Facilities for Effective Implementation of Competence-Based Curriculum in Public Secondary Schools in Arumeru District, Tanzania
}

\author{
Daniel Kosia Mokoro \\ Tumaini University Makumira, Tanzania \\ *Corresponding author: danielkosia@yahoo.com
}

\begin{abstract}
The purpose of this study was to find out the extent to which implementation of competence based curriculum (CBC) is adequately supported by laboratory facilities in public secondary schools in Arumeru District in Tanzania. Convergent parallel mixed method design was applied in the study. The study sampled 111 teachers, 177 students, 9 head of schools and 9 academic masters/mistresses making a total sample size of 306 respondents. Stratified-random sampling technique was used to select students and teachers whereas a purposive sampling technique was used to select heads of schools and academic masters/mistresses. Data were collected using questionnaires, interview guide, observation checklist and focus group discussion (FGD) guide. Data analysis was done using descriptive statistics and thematic analysis. The study established that, laboratory facilities were not adequate in the schools hence it was concluded that, the competence-based curriculum is not effectively implemented in the studied schools due to shortage of laboratory facilities. It was therefore recommended that the government in collaboration with other educational stakeholders should establish the required laboratory facilities for effective implementation of the competence- based in the schools.
\end{abstract}

Key words: Competence-based curriculum, implementation, laboratory facilities, Arumeru

Tanzania

\section{Introduction}

This study was propelled by the fact that previous studies conducted in Tanzania showed that the implementation of Competence-Based Curriculum (CBC) has remained traditional and not effective. Examples of these studies include that of Nyoni (2018) who assessed the challenges facing teachers in implementation of the paradigm shift towards a competence-based curriculum in Iringa region. The study revealed that, teachers were aware of the paradigm shift but most of them did not implement due to factors such as lack of teaching and learning resources and poor level of language proficiency on the part of some teachers and most students. A study by Makunja (2015) analyzed the challenges facing teachers in implementation of the $C B C$ in secondary schools in Morogoro. The findings showed that, effective implementation of the curriculum is affected by lack of in-service training to teachers, lack of knowledge and understanding of $C B C$, low quality of students joining secondary schools and students' reluctance to accept competence-based curriculum. Furthermore, Komba and Mwandanji (2015) investigated about the implementation of the $C B C$ in secondary schools in Morogoro and found that, most teachers did not have proper understanding of the objectives of the $\mathrm{CBC}$. The study concluded that, the implementation of the curriculum in schools was ineffective.

In the context of the current study, the literature is silent about any empirical research conducted in Arumeru district on the implementation of the competence-based curriculum in secondary schools. Though studies in other regions in the Tanzanian context have established that the implementation of the curriculum is ineffective, the effective 
implementation of the CBC has not been investigated by the previous studies. Reviewed literature indicated no research that investigated about the situation in secondary schools in Arumeru District. It is against this background that, the current study sought to investigate on laboratory facilities as determinants of effective implementation of the CBC in Tanzania, particularly in secondary schools of Arumeru District.

The competence-based curriculum in Tanzania is an innovation intended to enhance skills and competencies among secondary school students. Although studies in the Tanzanian context show that the implementation of $C B C$ is not effective, these studies mainly focused on the teaching approaches and most of them covered the tertiary and university level context (Paulo, 2014; Kavindi, 2014; Tambwe, 2017; Nzima, 2016). These studies revealed that, tutors are aware of the $\mathrm{CBC}$ concepts but the classroom practice shows the opposite whereby traditional teaching approaches are dominant. In so far as $\mathrm{CBC}$ implementation in secondary schools is concerned, few studies such as that of Makunja (2015) and that of Komba and Mwandanji (2015) addressed the issue in Morogoro apart from one (Muneja, 2015) which was conducted in Arusha Region where the this study has been conducted. Further, some of these studies employed the case study design with small samples, making the results not generalizable beyond the specific case context. None of the reviewed studies was conducted in Arumeru District, yet the National Examination Council of Tanzania (NECTA) database shows relatively poor performance of public secondary schools in the District for the past four years as $16.2 \%$ of the schools scored divisions 1 to 3 on average while $63.7 \%$ of private schools scored the same divisions on average (NECTA, 2018). The study therefore investigated about the adequacy of laboratory facilities in connection to effective implementation of the competence-based curriculum in public secondary schools in Arumeru District.

\section{Literature Review}

Laboratory facilities play a significant role in determining curriculum implementation effectiveness. Teachers' use of these facilities is therefore the key factor to influencing the curriculum implementation outcomes. Ngozi and Salisu (2015) carried out a study to find out the availability and utilization of laboratory facilities in senior secondary schools in Zaria metropolis of Kaduna State, Nigeria. The study used a descriptive survey design and the population of the study comprised of 12 government secondary schools. The study established that, of 135 Biology laboratories required, only 51 on average were available in the schools. The majority of teachers (68.8\%) expressed dissatisfaction with the number of laboratories available in the schools. Out of 16 respondent teachers, 14 (87.5\%) mentioned that they improvise for laboratory facilities in their schools. These means that, teachers apply their innovative skills and knowledge to ensure resources are made from local environment to enable learning to take place. Also, $51.8 \%$ of students indicated that, teachers did not hold practical lessons while only $28.2 \%$ indicated that teachers held practical lessons. This suggests a possibility that practical activities are carried out due to laboratory facilities inefficiency. Further, 10 (62\%) of the teachers stated that, they occasionally utilized laboratory facilities while $3(18.7 \%)$ utilize the facilities always and $18.7 \%$ utilize the facilities most of the time.

Alufohai and Aziegbe (2016) investigated about the influence of French Language laboratory on students' academic achievement in French in Nigeria. The study used a pretest-posttest control group quasi-experimental research design. The results showed that, students taught in the language laboratory plus classrooms achieved better in French language than those taught in the classroom only. It was thus concluded that, language laboratory is very important in effective implementation of the French curriculum.

In India, Mercy (2016) investigated on the effectiveness of using language laboratory in teaching English among standard VII students in Combatore District. The study employed experimental design with a sample of 64 students. Achievement test was used to collect data. Data analysis involved descriptive and inferential statistics (t-test) by comparing the means of experimental and control groups. The results of the study indicated that, language laboratory enabled students to gain more knowledge in English and that there was a significant difference between post-test scores of the experimental group and control group of students. A research by Mohamed (2017) determined the relationship between language laboratories and effective ways of mastering better performance in English language in Saudi Arabia. Students were subjected to pre-test first then 
taught using audio-visual active and recordingplayback, earphones and microphones. A post-test was then administered and the ANOVA correlation results showed that, the difference in score marks of the pretest and post-test was significant. The posttest scores were better than the pretest scores. A study by Mikanjuola and Sidiq (2013) assessed the vital facilities and infrastructure available for effective teaching and learning of Geography in senior secondary schools in Ekiti State, Nigeria. The findings showed that, all the schools (100\%) lacked Geography laboratory.

To sum up, the reviewed studies were conducted outside Tanzania and therefore this study addressed this gap by investigating on the availability of laboratories toward effective implementation of the competence-based curriculum in public secondary schools in Arumeru District. None of studies in the reviewed literature were conducted in Arumeru District. The current study therefore sought to investigate about the laboratory facilities as determinants of effective implementation of $C B C$ in public secondary school in Arumeru District.

\section{Methodology of the Study}

The study adopted a mixed-method design known as convergent parallel design. This is a single-phase approach where the researcher collects both quantitative and qualitative data, analyzes them separately then compares to see if the findings confirm or disconfirm each other (Creswell \& Creswell, 2018). The convergent parallel design enables the researcher to triangulate the methods by directly comparing and contrasting quantitative statistical results with qualitative findings for corroboration and validation purposes (Creswell \& Clark, 2011). The convergent parallel design was preferred as it allowed the collection of both quantitative data and qualitative data for corroboration purposes. The mixed method design helps to address the weakness of each design hence the mixed designs complement each other.

Population is a larger group to which one hopes to apply the results (Fraenkel, Wallen \& Hyun, 2015). The study had a population consisting of heads of schools, academic masters/mistresses, teachers and students. The heads of schools population consisted of 6 females and 29 males. The total teachers' population was 1193. The sample included 9 heads of schools, and 9 academic masters/mistresses, 111 teachers and 177 students making a total sample size of 306.

\section{Findings and Discussion}

The collected data were analyzed and presented according the research questions which guided this study.

\section{Categorization of respondents by gender}

This section presents the demographic data for respondents. Table 1 shows the respondents who participated in the study as categorized by gender.

Table 1: Respondents by Gender

\begin{tabular}{lll}
\hline Category & Frequency & Percent \\
\hline Teachers & & \\
Male & 63 & $56.8 \%$ \\
Female & 48 & 43.2 \\
Total & 111 & 100 \\
Students & & \\
$\quad$ Male & 91 & 52.3 \\
Female & 83 & 47.7 \\
Total & 174 & 100 \\
School Heads & & \\
Male & 8 & 88.9 \\
Female & 1 & 11.1 \\
Total & 9 & 100 \\
Academic Masters & & \\
Male & 7 & 77.8 \\
Female & 2 & 22.2 \\
Total & 9 & 100 \\
\hline
\end{tabular}

According to Table 1 , more males $(56.8 \%)$ than female $(43.2 \%)$ teachers participated in the study. This was based on the proportions of male and female teachers in the populations whereby males' proportion is slightly higher than that of females. For students, 91 (52.3\%) males and 83 (47.7\%) females participated in the study. The researcher sampled equal male and female students who were given questionnaires in the studied schools. However, the difference in their proportions was attributed by questionnaires return rate whereby more questionnaires from female students were not returned leading to the difference. The table also shows that, a majority of heads of schools at the studied secondary schools were male (88.9\%). Very few female teachers as is the case of $1(11.1 \%)$ are in the head of school position. Similarly, a majority of academic masters and mistresses who participated in this study were males (77.8\%). Of the 9 academic masters and mistresses involved in the study, only $2(22.2 \%)$ females were holding academic officer position in the studied schools.

\section{Adequacy of Laboratory facilities}

The study inquired from various respondents about the adequacy of laboratory facilities in their schools. The respondents were teachers, students, heads of 
schools and academic masters/mistresses. Tables 2

facilities based on the teachers' questionnaire presents the findings about adequacy of laboratory

responses.

Table 2: Teachers' responses about the adequacy of laboratory facilities in their schools

\begin{tabular}{lcccccc}
\hline Facility & \multicolumn{2}{c}{ Very adequate } & \multicolumn{2}{c}{ Adequate } & \multicolumn{2}{c}{ Inadequate } \\
\hline & Frequency & Percent & Frequency & Percent & Frequency & Percentage \\
Science laboratories $(n=26)$ & 6 & 23.1 & 14 & 53.8 & 6 & 23.1 \\
Computer laboratories & 2 & 2.4 & 6 & 7.2 & 75 & 67.6 \\
(n=83) & & & & & & \\
Language lab $(\mathrm{n}=86)$ & 3 & 3.5 & 2 & 2.3 & 81 & 94.2 \\
Geography lab $(\mathrm{n}=87)$ & & & 5 & 5.7 & 82 & 94.3 \\
\hline
\end{tabular}

Table 3: Observation Checklist data on Availability of Laboratories in schools

\begin{tabular}{llcc}
\hline Facility & Quantity & No. Schools & Percentage \\
\hline \multirow{3}{*}{ Science Labs } & Three labs & 2 & 22 \\
& Two labs & 2 & 22 \\
Computer Lab & One laboratory & 5 & 55 \\
& One & 1 & 11 \\
Geography Lab & Not available & 8 & 89 \\
Languages Lab & None available & 9 & 100 \\
\hline
\end{tabular}

Table 2, shows that a majority of science teachers i.e. $14(53.8 \%)$ responded that the laboratories are adequate. Other, $6(23 \%)$ even rated the science laboratories very adequate. In addition, a majority of teachers $(94.2 \%$ and $94.3 \%)$ stated that the Language and Geography laboratories respectively are not adequate in the secondary schools. The availability of laboratory facilities in the schools was further measured through the use of an observation checklist by the researcher as summarized in Table three.

Data from the observation checklist in Table 3 show the quantities of science laboratories available in the studied public secondary schools. Most schools (55\%) had only one science laboratory. It was also revealed that $22 \%$ had two and another $22 \%$ had three laboratories. The finding implies that, the science laboratories are below the required number whereby three laboratories are required for the three natural science subjects namely; Biology, Chemistry and Physics. This situation affects the efficiency of teaching as students and teachers have to alternate in using the same facilities for practical sessions. Furthermore, it was found that Language and Geography laboratory facilities were not available at all the nine studied secondary schools.

The qualitative data from interview with heads of schools revealed that science laboratories are inadequate in studied secondary schools. Thematic analysis of qualitative data captured using interview and focus group discussion guides revealed the following findings about the adequacy of science laboratories in schools, inadequate laboratories and space, inadequate laboratory supplies, and deficiency of human resource (teachers) in science subjects.

One of the findings which came out from the thematic analysis of the interview and focus group discussion (FGD) further revealed the inadequacy of science laboratories. Focus group discussions were conducted in two of the sampled public secondary schools. By coincidence, both secondary schools had 3 science laboratories, for Biology, Chemistry and Physics subjects. Even with the existence of the three laboratories, the focus group discussion members expressed that, the laboratory space did not accommodate all students of a particular class for experimental activities. This implies that the practical learning may not succeed as expected due to large number of students in the practical sessions. One of the focus group discussion teachers elaborated this point as follows: "for the laboratory buildings, we have three but there are challenges e.g. students are forced to be congested in doing experiments especially in Biology where all students study it" (FGDT2).

The data imply that, the situation in the laboratories may hinder effective learning as some students lack the opportunity to participate in experiments and making observations effectively. Learning becomes effective when learners take part by setting the experiments, making observations and recording. Due to big number of students in secondary schools, 
practical sessions are affected and this forces a teacher to sometimes change the mode of practical to demonstration by the teacher where students observe in groups of 10 or more. This is similar to the finding by Mukami (2015) in Kenya who established that the main activities in the laboratories were teacher demonstration due to an unusual big number of students.

Nevertheless, the members of the groups expressed that, schools have never failed to do practical examinations despite the science resources shortage. This is a significant observation that schools are doing all possible means to make sure learners do the actual practical examinations instead of 'alternative to practical' (NECTA, 2019) whereby practical questions are asked and learners attempt theoretically than doing the actual experiments.

The interviews with heads of schools also revealed that the schools had inadequate numbers of laboratories and also some are incomplete in terms of gas and water systems, storage rooms and fumes chambers. This finding agrees with that by Mukami (2015) in Kenya who found that some available science laboratories in secondary schools in Meru South District were lacking vital requirements like fume chambers, first aid kit, gas taps and running water. The inadequacy of science laboratories is likely to affect the implementation of the competence based curriculum in schools.

Several interviewees expressed about how inadequacy of science laboratories is affecting learning in schools. One interviewee for example explained about the effect of sharing laboratory room among different subjects as follows: "the sharing of laboratories between A-level and O-level students is affecting learning as students don't get enough time to use the laboratories due to sharing" (Interviewee 1). The A-Level students follow their own curriculum which is different from the O-level (two different cycles of education). Thus the laboratory sharing is likely to inconvenience each class level in planning and conducting experiments within the same laboratory buildings as the other group will get delayed to cover the required experiments. This makes laboratory a limited and scarce facility as both levels of education rely on the limited laboratory facility due to inadequate numbers of laboratories. The presence of a single science laboratory in a school made the laboratory become a scarce resource due to different science subjects relying on the same facility. The interviewee illustrated this by saying: "Being one laboratory in the school, this becomes a scarce resource as when one subject is using the room, the other subjects are affected. About the laboratory resources, we thank the government now we have a lot of supplies; but we now miss the buildings" (Interviewee 3). This datum shows that, science laboratories become a challenge in the implementation of the competence based curriculum as these facilities are inadequate in the schools though the laboratory supplies may be adequate. The laboratory resources need to be well organized, stored appropriated and used appropriately for learning activities. Having a single laboratory building creates more space deficiency as the resources/supplies for different science subjects are mixed up in the available space.

This finding about the science laboratories adequacy in secondary schools agrees with that by Achimungu (2016) in Nigeria who also found that, the lack of science laboratories and inadequate infrastructure affected the implementation of Chemistry curriculum in secondary schools. The results also support the findings of two studies (Zengele \& Alemeyahu, 2016; Daba \& Anbesaw, 2016) which found that, secondary schools lacked laboratory rooms and separate laboratories for sciences respectively in Ethiopia. The contexts of the three studies are similar as all represent the developing countries whereby the infrastructures for science facilities may not be well established. The finding is also similar to that of Pareek (2019) which established that most studied secondary schools in India did not have separate science laboratories and that only one of the 21 studied secondary schools had one functional science laboratory.

\begin{tabular}{lcc}
\multicolumn{3}{c}{ Table 4: Availability of computer laboratory } \\
\hline Response & Frequency & Percent \\
\hline Available & 25 & $14.5 \%$ \\
Not available & 148 & $85.5 \%$ \\
Total & 173 & $100 \%$ \\
\hline
\end{tabular}

As Table 4 shows, a majority (85.5\%) of students mentioned that their schools are lacking computer laboratories. Few students (14.5\%) said the schools had computer laboratories. Data from observation checklist also show similar finding as only one school had a computer laboratory. Absence of this facility in schools may make the schools lag behind in gaining computer literacy skills which are among the $\mathrm{CBC}$ competencies. Thematic analysis of qualitative 
data also revealed that "lack of computer laboratory facilities" influence the effective implementation of the curriculum.

The FGD with teachers revealed that, schools lacked computer laboratories and computers. Only the administrators' offices had one computer to serve the whole school. In one FGD, it was mentioned that the school had a Liquid Crystal Display (LCD) projector and the resource is helping teachers to display notes and experimental procedures in classes. This is commendable as it adds efficiency to the teaching process and adds value to learning through seeing instead of just hearing. The resource complements the traditional way of teaching through teacher talk or lecture.

Both FGD groups expressed that, the integration of ICT in teaching/learning is affected by absence of computers and internet in their schools. A research by Ghaviefekr and Rosdy (2015) in Malaysia noted that, technology-based teaching and learning in schools is more effective than the traditional classroom. Some teachers who participated in the current study stated that, they sometime try downloading materials using their phones but the use is affected by lack of computer facilities. In explaining the importance of computers and internet, one member said:

It is important to have a computer laboratory to enable students to search materials. The Library and computer laboratories are not separable. This is a problem in our school. When a student cannot find a book in the library, a student can shift to searching the material in the computer that is connected with the internet (FGDT).

The lack of computers in schools makes learners ignorant of current technology and achievement of computer literacy competence among secondary school students will just be a dream not achievable. The Ministry of Education should therefore think about this competence and develop materials and human resources in this aspect so as to equip secondary school community with computing skills.

Students' responses supported those from teachers and the observation checklist. When asked about the availability of Geography and Language laboratories in their schools nearly all indicated that these laboratories are not available. Their responses are summarized in Table 5.

Table 5: Students' responses about availability of Geography and Language Laboratories

\begin{tabular}{llccc}
\hline Laboratory & & Available & \multicolumn{2}{c}{ Not available } \\
& Frequency & Percentage & Frequency & Percent \\
\hline Geography & 8 & 4.6 & 165 & 95.4 \\
Languages & 5 & 2.9 & 173 & 97.1 \\
\hline
\end{tabular}

With reference to Table 5, most students mentioned that their schools do not have Geography and Language laboratories $(95.4 \%$ and $97.1 \%)$ respectively. Very few students who mentioned that these facilities are available possibly they don't understand what these facilities are. The finding of the current study is similar to the finding by Mwesiga (2017) in Morogoro which showed that, four community secondary schools studied did not have a Geography laboratory except the existence of at least a Geography resource room in one school. The results are also similar to the findings by Mikanjuola and Sidiq (2013) in Nigeria who found that, in 43 studied secondary schools, all the 43 did not have a Geography laboratory among other facilities missing. This suggests that Geography laboratories are not common in schools. A research study by Aluofohai, and Aziegbe (2016) in Nigerian secondary schools established that students taught in the laboratory and classroom achieved better in
French language than those taught only in the classroom. Also in India, Mercy (2016) proved that, language laboratory supported learning positively when compared to traditional method as it impacted positively on the teaching of English language in primary schools in the country.

These findings imply that, the laboratory facilities for the mentioned non-science subjects are not of the priority by educational stakeholders. This may be due to the notion that there are no practical activities or papers in those subjects during examinations. This also shows that, there is knowledge gap between curriculum developers and the implementers since these laboratory facilities were included among the facilities required in secondary education competence based curriculum in Tanzania.

Due to the absence of Geography laboratory in secondary schools, secondary school students will 
continue missing learning important aspects that would best be learned though practical sessions for acquisitions of geographical skills. In responding to the teachers' questionnaire, a teacher mentioned the consequences such as: "absence of Geography laboratory leads to students learning just theoretically and cause many students to fail in examinations (Respondent 80).

Respondents also stated that; lack of language laboratories impacts negatively on students' effective acquisition of communication and language skills. The impact is illustrated by the following statements from teachers: ".... absence of language lab causes students to fail to master language effectively" (Respondent 80). Other teacher added saying: "not having language laboratory makes students not understand about how speech is made from articulators and necessary parts for speech formation" (Respondent 78).

\section{Conclusions and recommendations}

Most schools did not have the required number of science and computer laboratories and none of the schools had the Geography and Languages laboratories which are required by the current curriculum. The study therefore, concludes that, effective implementation of the competence based curriculum is negatively affected by shortage and lack of the laboratories. Under such circumstances, the competence-based curriculum cannot realize its expected outcomes unless the required laboratory facilities such as laboratories are adequately procured in secondary schools.

The shortage or absence of the required laboratory facilities, make learning to be just theoretical than practical, leading to congestion in practical sessions which may cause poor performance in examinations.

The shortage of laboratory facilities and equipment created a competition between A-Level and O-level students in using the same. Furthermore, lack of Geography and Language laboratories hindered effective development and acquisition of required skills in those subjects.

The study recommend that the Ministry of Education, Science and Technology should come up with a policy that ensures that, the laboratory facilities and teaching-learning resources required for curriculum implementation are established procured and used effectively in the schools.
The government should also collaborate with stakeholders such as community to establish all the required facilities such as Science, Geography, language and computer laboratories.

\section{Reference}

Achimungu, L. (2016). Factors Affecting the Effective Implementation of Senior Secondary Education Chemistry Curriculum in Kogi State, Nigeria. International Journal of Scientific and Research Publications. 6 (5), 562-566.

Aluofohai, P.J. and Aziegbe, M. (2016). The influence of Language Laboratory in the academic Achievement of Students in French Language in Edo state secondary school. European Journal of Language Studies, 3 (2), 75-80.

Creswell, J. W. and Creswell, J. D. (2018). Research Designs: Qualitative, Quantitative \& Mixed Methods Approaches ( $\left.5^{\text {th }} E d.\right)$. London: SAGE Publications.

Creswell, J. \& Clark, P. (2011). Designing \& Conducting MMR. Thousand Oaks: SAGE

Daba, T. M. and Anbesaw, M. S. (2016) Factors Affecting Implementation of Practical Activities in Science education in Some Selected Secondary and Preparatory Schools of Afar Region, North East Ethiopia. International Journal of Environmental \& Ecience Education, 11 (12), 5438-5452

Fraenkel, J.R, Wallen, N.E., and Hyun, H.H. (2015). How to Design and Evaluate Research in Education ( $\left.9^{\text {th }} E d.\right)$. New York: McGraw-Hill Education.

Ghavifekr, S. \& Rosdy, W.A.W. (2015). Teaching and learning with technology: Effectiveness of ICT integration in schools. International Journal of Research in Education and Science (IJRES), 1(2), 175-191.

Kavindi, A.E. (2014). The Implementation of Competence Based Curriculum in Certificate Teachers Colleges in Tanzania: The Case of Two Teachers Colleges in Mbeya Region. Med Thesis. University of Oslo.

Komba, C.S. \& Mwandanji M. (2015) Reflection on the implementation of Competence Based Curriculum in Tanzanian secondary schools. Journal of Education and Learning; 4 (2) 7380 
Makunja, G. (2015). Adopting Competence -Based Curriculum to Improve Quality of Secondary Education in Tanzania: "Is it a Dream or Reality"? International Journal of Education and Research, 3 (11), 185-188.

Mukami, N.E.(2015). Extent of utilization of laboratories in teaching and learning chemistry in public secondary schools in Meru south district, Kenya. MED Thesis. Nairbo: Kenyata University.

Makunja, G. (2015). Adopting Competence -Based Curriculum to Improve Quality of Secondary Education in Tanzania: "Is it a Dream or Reality"? International Journal of Education and Research, 3 (11), 185-188.

Mercy, M. (2016). Effectiveness of using language laboratory in teaching English among standard six students in Coimbatore district. International Journal of ResearchGranthaalayah, 4 (5), 22-26.

Mikanjuola, S.A. and Sidiq, O. B. (2013). Geography laboratory and observation centre: The missing vital infrastructure for effective teaching of geography in school. Afro Asian Journal of Social Sciences, 4 (4), 1-11.

Mohammed, A. (2017). The Role of Language Laboratory in English Language Learning Settings. English Language Teaching, 10 (2), 86-93.

Muneja, M. S. (2015). Secondary School Teachers Implementation of the Competence Based Curriculum in Arusha Region, Tanzania. University of South Africa

Mwesiga, F. (2017). Factors influencing students' poor performance in geography subject in Tanzania: The case of community secondary schools in Morogoro municipality. MAED Thesis. Morogoro: Mzumbe University.

NECTA (2018). Ranking of District Councils based on Certificate of Secondary Education Examination Results. Dar es Salaam:

MoEST.NECTA (2019). Certificate of Secondary Education Examination Formats. Dar-esSalaam: National Examination Council of Tanzania.
Ngozi, D and Salisu H. (2015) Inadequate Laboratory Facilities and Utilization: Pedagogical Hindrance to Students' Academic Performance in Biology in Senior Secondary Certificate Examination in Zaria Metropolis, Kaduna State, Nigeria. International Business Research, 8 (9).124-134

Nwosu, V. (2019). Teachers' perception of the use of language laboratories in English Language teaching and learning in Obio/Akpor Iga. International Journal of Education and Evaluation, 5 (1), 31-40.

Nyoni, Z .K. (2018) Challenges Facing Teachers in Tanzania: the implementation of the paradigm shift towards a competence-based curriculum in public secondary schools in Iringa municipality. Kervan-International Journal of Afro-Asiatic studies, 1 (22), 195215.

Nzima, I. (2016). Competence- Based Curriculum (CBC) in Tanzania: Tutors' Understanding and their Instructional Practices. Doctoral Dissertation. Linneaus: Linneaus University Press.

Pareek, R. B. (2019). An Assessment of Availability and Utilization of Laboratory Facilities for Teaching Science at Secondary Level. Science Education International, 30 (1), 7581

Paulo, A. (2014). Pre-service Teachers Preparedness to Implement Competence Based Curriculum in Secondary Schools in Tanzania. International Journal of Education Research. 2 (7), 219 -230.

Tambwe, M. A. (2017). Challenges facing implementation of Competence -Based Education and Training (CBET) system in Tanzanian Technical Institutions. Education Research Journal, 7(11), 277-283.

Zengele, A. G. and Alemayehu B. (2016). The Status of Secondary School Science Laboratory Activities for Quality Education in Case of Wolaita Zone, Southern Ethiopia. Journal of Education and Practice, 7 (31), 1-11. 